\title{
Spinal Anesthesia for Noncardiac Surgery in High-Risk Infants With Corrected Tetralogy of Fallot and Cardiomyopathy
}

\author{
Ozkan Onal ${ }^{1,}$; Fatmanur Erdogdu ${ }^{1}$; Derya Cimen $^{2}$; Ilhan Ciftci $^{3}$; Seza Apiliogullari ${ }^{1}$ \\ ${ }_{1}^{1}$ Department of Anesthesia and Intensive Care, Selcuk University Medical Faculty, Konya, Turkey \\ ${ }_{2}^{2}$ Department of Pediatric Cardiology Konya, Selcuk University Medical Faculty, Konya, Turkey \\ ${ }^{3}$ Department of Pediatric Surgery, Selcuk University Medical Faculty, Konya, Turkey \\ ${ }^{*}$ Corresponding author: Ozkan Onal, Department of Anesthesia and Intensive Care, Selcuk University Medical Faculty, Konya, Turkey. Tel: $+90-5059052252$, Fax: $+90-3323252729$, \\ E-mail: drozkanonal@selcuk.edu.tr
}

Received: December 2, 2014; Revised: December 30, 2014; Accepted: January 10, 2015

Keywords: Spinal Anesthesia; Infant; Cardiomyopathy

\section{Dear Editor,}

We present a case of successful spinal anesthesia for a noncardiac surgery (NCS) featuring cardiomyopathy with corrected tetralogy of Fallot (TOF).

A 29-month-old boy weighing $12.500 \mathrm{~g}$, american society of anesthesiologists (ASA) physical status III required the following: bilateral orchiopexy, inguinal hernia repair, and umbilical hernia repair. He was operated on for TOF a few months ago and before the surgery we describe here, suffered from residual pulmonic stenosis and right ventricle (RV) dysfunction. The RV end-diastolic and RV endsystolic areas were high, the residual pulmonic stenosis gradient was $45 \mathrm{mmHg}$, the E/A ratio of the tricuspid valve was reversed, and regurgitation of the pulmonary valve was visible. The Doppler echocardiogram revealed that the myocardial performance index from the lateral tricuspid annulus of the right ventricle was 0.54. The patient had no other known diseases and no established condition to contraindicate for spinal anesthesia (SA).

The parents were given information on SA and their written informed consent was received. In the operating room, the patient received continuous electrocardiogram, pulse oximetry, noninvasive blood pressure, and temperature monitoring. Readings were recorded every five minutes. The patient's baseline heart rate was 127 beats. $\mathrm{min}^{-1}$, his blood pressure was $125.79 \mathrm{mmHg}$, his $\mathrm{SpO} 2$ was $96 \%$, and his skin temperature was $33.2^{\circ} \mathrm{C}$. Hydration was started with mixed pediatric solution (izomix 1/3 biofleks osel include $3.3 \mathrm{~g}$ dextrose monohydrate and $0.3 \mathrm{~g}$ sodium chloride per $100 \mathrm{~g}$ ) intravenously at a rate of $5 \mathrm{~mL} / \mathrm{kg} / \mathrm{s}$.

The patient was sedated with sevoflurane in a $50 \% \mathrm{~N}_{2} \mathrm{O}$ - 50\% $\mathrm{O}_{2}$ mixture during spontaneous breathing via a facemask. After establishing peripheral intravenous access, the patient was placed in the left lateral knee-chest position. An experienced anesthesiologist (more than 500 pediatric spinal blocks) performed a lumbar puncture at the L4-L5 interspace with a disposable $25 \mathrm{G} \times 90$ mm Quincke spinal needle. Sevoflurane administration was stopped after it was confirmed that the patient experienced flexia during the skin puncture. Preservative-free $0.5 \mathrm{mg} / \mathrm{kg}^{-1}$ of $0.5 \%$ bupivacaine was injected at a rate of $0.1 \mathrm{~mL} / \mathrm{s}$. The needle was withdrawn after maintaining it in the position for 10 seconds.

Surgery was initiated after it was confirmed by pinprick that the patient did not feel pain in the inguinal area. Sensory block levels were not tested to avoid patient discomfort. Spontaneous breathing was maintained with supplementary oxygen through a facemask during the operation. Paracetamol (Parol Atabay, Turkey; include 10 mg paracetamol per $1 \mathrm{cc}) 20 \mathrm{mg} / \mathrm{kg}^{-1}$ was infused during the first 20 minutes of surgery for postoperative analgesia. The patient was asleep during the procedure and did not require additional sedation. When the systolic blood pressure was decreased to $92 \mathrm{mmHg}$, an additional intravenous bolus of $25 \mathrm{~mL}$ of mixed solution was initiated 20 minutes after the spinal block. The surgery lasted for 40 minutes. Hypertension, tachycardia, bradycardia, hypoxemia, or apneas were not observed during surgery. The patient was awakened by tactile stimulation and then taken to the anesthesia recovery room along with his mother to ensure calm. Motor block was recovered 75 minutes after spinal block. The patient was discharged from the hospital uneventfully the day after the operation.

Congenital heart diseases(CHDs) are the most prevalent group of congenital anomalies and affect approximately 79.7 per 10,000 live-born infants (1). Children with CHDs often require surgical intervention for abdominal condi-

Copyright (C2015, Iranian Society of Regional Anesthesia and Pain Medicine(ISRAPM). This is an open-access article distributed under the terms of the Creative Commons Attribution-NonCommercial 4.0 International License (http://creativecommons.org/licenses/by-nc/4.0/) which permits copy and redistribute the material just in noncommercial usages, provided the original work is properly cited. 
tions (2). The risk is greatest in neonates and infants, in whom mortality associated with NCS is two times higher in the presence of a CHD (3). Adverse events, such as cardiac arrest, bradycardia, arrhythmia, and hypotension can be predicted in infants who are less than 1-year-old, in children whose ASA physical status is high, and in patients who are endotracheally intubated and mechanically ventilated (4). For patients with cardiomyopathy, pulmonary hypertension, preoperative cyanosis, congestive heart failure, aortic stenosis, or Williams syndrome, NCS is associated with higher rates of complications than other CHDs (5).

Spinal anesthesia and caudal anesthesia have a low incidence of complications and a high degree of cardiorespiratory stability $(6,7)$ compared with the caudal anesthesia that is commonly used in pediatric practice (7); the rapid onset of impact and the ability to easily reach high levels prompted us to choose spinal anesthesia for this patient who was scheduled for orchiopexy and umbilical hernia operations. Prior limited case reports describe the successful use of SA for NCS in pediatric patients with CHDs $(5,8,9)$ and this case study further strengthens that data. This type of anesthesia should be used in children who are at high risk during general anesthesia (10).

In conclusion, pediatric SA is a technique that should not be omitted when treating high-risk cardiac patients.

\section{Authors' Contributions}

Drafting of the manuscript: Ozkan Onal, Seza Apiliogullari; critical revision of the manuscript for important intellectual content: Ozkan Onal, Seza Apiliogullari,
Fatmanur Erdogdu. Obtaining the data: Derya Cimen and Ilhan Ciftci.

\section{References}

1. Dadvand P, Rankin J, Shirley MDF, Rushton S, Pless-Mulloli T. Descriptive epidemiology of congenital heart disease in Northern England. Paediatr Perinat Epidemiol. 2009;23(1):58-65.

2. Gillory LA, Megison ML, Harmon CM, Chen MK, Anderson S, Chong AJ, et al. Laparoscopic surgery in children with congenital heart disease. J Pediatr Surg. 2012;47(6):1084-8.

3. Baum VC, Barton DM, Gutgesell HP. Influence of congenital heart disease on mortality after noncardiac surgery in hospitalized children. Pediatr. 2000;105(2):332-5.

4. Somri M, Coran AG, Mattar I, Teszler C, Shaoul R, Tomkins O, et al. The postoperative occurrence of cardio-respiratory adverse events in small infants undergoing gastrointestinal surgery: prospective comparison of general anesthesia and combined spinal-epidural anesthesia. Pediatr Surg Int. 2011;27(11):1173-8.

5. Kachko L, Simhi E, Tzeitlin E, Freud E, Katz J. Spinal anesthesia for noncardiac surgery in infants with congenital heart diseases. Paediatr Anaesth. 2012;22(7):647-53.

6. Ciftci I, Apiliogullari S, Kara I, Gunduz E, Duman A. Repair of duodenal atresia under spinal anesthesia in a low-birth-weight preterm neonate: case report. J pediatr surg. 2012;47(8):33-5.

7. Uguralp S, Mutus M, Koroglu A, Gurbuz N, Koltuksuz U, Demircan $M$. Regional anesthesia is a good alternative to general anesthesia in pediatric surgery: Experience in 1,554 children. $J$ Pediatr Surg. 2002;37(4):610-3.

8. Williams RK, Adams DC, Aladjem EV, Kreutz JM, Sartorelli KH, Vane DW, et al. The safety and efficacy of spinal anesthesia for surgery in infants: the Vermont Infant Spinal Registry. Anesth Analg. 2006;102(1):67-71.

9. Astuto M, Sapienza D, Di Benedetto V, Disma N. Spinal anesthesia for inguinal hernia repair in an infant with Williams syndrome: case report. Paediatr Anaesth. 2007;17(2):193-5.

10. Onal O, Apiliogulları S, Gunduz E, Celik JB, Senaran H. Spinal anaesthesia for orthopaedic surgery in children with cerebral palsy: Analysis of 36 patients. PakJ Med Sci. 2015;31(1):189-93. 